\title{
Liquid Phase Therapy with Localized High-Concentration Electrolytes for Solid-State Li Metal Pouch Cells
}

\author{
Gaolong Zhu ${ }^{1,2,3,5}$, Chenzi Zhao ${ }^{3}$, Hong Yuan ${ }^{1}$, Haoxiong Nan ${ }^{3,4}$, Bochen Zhao ${ }^{3}$, Lipeng Hou ${ }^{3}$, \\ Chuangxin $\mathrm{He}^{2}$, Quanbing Liu ${ }^{4}$, Jiaqi Huang ${ }^{1, *}$ \\ ${ }^{1}$ Advanced Research Institute of Multidisciplinary Science, Beijing Institute of Technology, Beijing 100081, China. \\ ${ }^{2}$ Shenzhen Key Laboratory of Functional Polymer, College of Chemistry and Chemical Engineering, Shenzhen University, Shenzhen \\ 518000, Guangdong Province, China. \\ ${ }^{3}$ Beijing Key Laboratory of Green Chemical Reaction Engineering and Technology, Department of Chemical Engineering, Tsinghua \\ University, Beijing 100084, China. \\ ${ }^{4}$ School of Chemical Engineering and Light Industry, Guangdong University of Technology, Guangzhou 510006, China. \\ ${ }^{5}$ Key Laboratory of Optoelectronic Devices Systems of Ministry of Education and Guangdong Province, College of Optoelectronic \\ Engineering, Shenzhen University, Shenzhen 518060, Guangdong Province, China.
}

\begin{abstract}
Solid-state Li metal batteries are considered promising next-generation energy storage systems due to its exceptional advantages in terms of safety and high energy density. The continuous process on the development of solid-state fast ionic electrolytes enables the solid-state battery to operate at room temperature. Among these, sulfide-based solid electrolytes have attracted significant attentions due to their extremely high ionic conductivity, excellent deformability, and mild lowtemperature processability. However, the full demonstration of practical batteries remains challenging due to the slow lithium-ion transport kinetics at working solidsolid interfaces. The sluggish interfacial transport kinetics mainly result from the

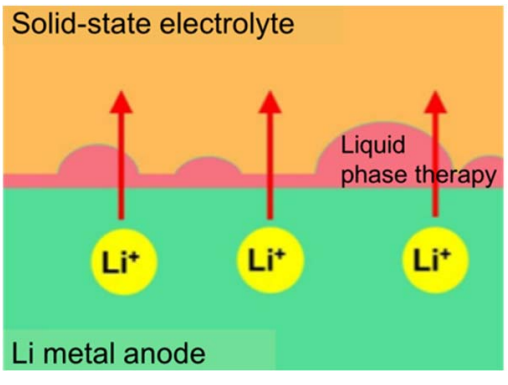
poor solid-solid contacts, resulting in poor battery performance. Especially for solid-state pouch cells, the high local current due to the poor contact is amplified by the high working current, leading to rapid failure. Constructing fast ion transport paths between the Li metal anode and solid electrolyte interface is key for the practical application of solid-state batteries. Here a simple protocol was developed to realize fast ionic transportation by wetting the solid electrolyte/Li metal anode interface with localized high salt concentration liquid electrolyte. First, $3.5 \mathrm{mmol}$ lithium trifluoroalfonylimide (LiTFSI) was added into 1,1,2,2-tetrafluoroethyl-2,2,3,3-tetrafluoropropyl ether (HFE) and dimethoxyethane (DME) mixed solvent, and stirred to obtain uniformly dispersed localized high-concentration liquid electrolyte, denoted as HFE-DME LiTFSI. The fluidity of liquid electrolyte ensures sufficiently conformal contacts between lithium anode and liquid electrolyte, as well as solid-state electrolyte and liquid electrolyte. Thus, fast ion transportation channels were constructed between the solid electrolyte and Li metal anode by wetting HFE-DME LiTFSI at a concentration of $3.0 \mu \mathrm{L} \cdot \mathrm{cm}^{-2}$. After liquid phase therapy, the interfacial resistance of solid-state $\mathrm{Li} \mid \mathrm{Li}_{4} \mathrm{Ti}_{5} \mathrm{O}_{12}$ (LTO) pouch cell rapidly reduced from 4366 to $64 \Omega \cdot \mathrm{cm}^{-2}$ and even lower than the cell that was pressed at $3 \mathrm{MPa}$ in the assemble process $\left(340 \Omega \cdot \mathrm{cm}^{-2}\right)$. This suggests that the ion transport kinetics are significantly improved by liquid phase therapy. Therefore, the solid-state Li metal pouch cell with dimensions of $30 \mathrm{~mm}$ $\times 30 \mathrm{~mm}$ showed excellent cycling performances with specific capacities of 107 and $96 \mathrm{mAh} \cdot \mathrm{g}^{-1}$ at $0.1 \mathrm{C}$ and $0.5 \mathrm{C}$, respectively. Furthermore, the solid-state Li-S pouch cell delivered capacities of 1100 and $932 \mathrm{mAh} \cdot \mathrm{g}^{-1}$ at $0.01 \mathrm{C}$ and $0.02 \mathrm{C}$, respectively. This study demonstrates the effectiveness of the novel liquid phase therapy to construct fast ionic transportation channels, which providing an effective strategy for the practical application of solid-state Li metal pouch cells.
\end{abstract}

Received: May 5, 2020; Revised: May 27, 2020; Accepted: June 10, 2020; Published online: June 18, 2020.

*Corresponding author. Email: jqhuang@bit.edu.cn.

The project was supported by the National Key Research and Development Program of China (2016YFA0202500, 2016YFA0200102), the National Natural Science Foundation of China (21676160, 21808124, U1801257), and the China Postdoctoral Science Foundation (2019T120098).

国家重点研发计划(2016YFA0202500, 2016YFA0200102), 国家自然科学基金(21676160, 21808124, U1801257), 博士后基金(2019T120098)资助项目 (C) Editorial office of Acta Physico-Chimica Sinica 
Key Words: Solid-state pouch cell; Lithium metal anode; Sulfide electrolyte; Liquid phase therapy

\title{
基于局部高盐界面润湿策略构筑的固态金属锂软包电池
}

\author{
朱高龙 ${ }^{1,2,3,5}$, 赵辰孜 ${ }^{3}$, 袁洪 ${ }^{1}$, 南皓雄 ${ }^{3,4}$, 赵铂琛 ${ }^{3}$, 侯立鹏 ${ }^{3}$, 何传新 ${ }^{2}$, 刘全兵 ${ }^{4}$, 黄佳琦 1 , * \\ 1 北京理工大学前沿交叉科学研究院, 北京 100081 \\ 2 深圳大学化学与化工学院, 功能高分子深圳市重点实验室, 广东深圳 518000 \\ 3 清华大学化学工程系, 绿色化学反应工程与技术北京市重点实验室, 北京 100084 \\ 4 广东工业大学轻工化工学院, 广州 510006 \\ 5 深圳大学光电工程学院, 光电子器件与系统(教育部/广东省)重点实验室, 广东深圳 518060
}

\begin{abstract}
摘要: 固态金属锂电池因其优异的安全性和高的理论能量密度被认为是最具前景的下一代储能电池体系之一。随着以硫 化物为代表的高离子导率电解质被逐渐开发, 金属锂与固态电解质界面成为限制固态电池应用的主要瓶颈。金属锂/电解 质的固固界面存在着界面接触差、界面电荷传输阻力高等问题。本文以固态金属锂软包电池为研究对象, 通过由 1,1,2,2四氟乙基-2,2,3,3-四氟丙基醚、乙二醇二甲醚与双三氟磺酰亚胺锂组成的局部高盐液态电解液(HFE-DME LiTFSI)对金属 锂/固态电解质界面进行润湿, 增加金属锂与固态电解质之间的离子接触, 降低离子传输阻力, 从而提高锂离子在界面的 传输能力。在 $30 \mathrm{~mm} \times 30 \mathrm{~mm} \mathrm{Li} \mid \mathrm{Li}_{4} \mathrm{Ti}_{5} \mathrm{O}_{12}$ (LTO)固态软包电池中, 通过 $3.0 \mu \mathrm{L} \cdot \mathrm{cm}^{-2} \mathrm{HFE}-\mathrm{DME}$ LiTFSI局部高盐液态电 解液润湿金属锂与固态电解质界面, 软包电池的界面电阻从 $4366 \Omega \cdot \mathrm{cm}^{-2}$ 降低到了 $64 \Omega \cdot \mathrm{cm}^{-2}$ 。在 $0.1 C$ 与 $0.5 C$ 倍率下, LTO的放电比容量分别达到 107 与 $96 \mathrm{mAh} \cdot \mathrm{g}^{-1}$ 。同时, Li-S固态软包电池在 $0.01 \mathrm{C}$ 及 $0.02 \mathrm{C}$, 比容量也达到了 1100 与 932 $\mathrm{mAh} \cdot \mathrm{g}^{-1}$ 。
\end{abstract}

关键词：固态软包电池；金属锂负极；硫化物电解质；界面润湿 中图分类号: 0646

\section{1 引言}

随着二次电池应用越来越广泛, 储能规模不 断攀升, 常规锂离子电池受其正、负极材料的能源 化学原理限制, 其能量密度已接近理论极限, 难以 满足快速发展的电子设备和新能源汽车市场对电 池高能量密度的要求 ${ }^{1-9}$ 。传统锂离子电池含有大 量有机液态电解液, 存在易泄漏、易腐蚀等问题, 且极易带来燃烧、爆炸等安全隐患 ${ }^{10,11}$ 。因此, 高 安全性、高能量密度储能电池是未来电池发展的 必然趋势 $12-20$ 。

固态电池以固态电解质 (SSE)作为隔膜和离 子通道，正极、负极、电解质均为固体，在冲击、 穿刺、高温等极端条件下也难以发生爆炸, 从而安 全性大幅提升 ${ }^{21-27}$ 。同时, SSE有望与高理论比容 量的金属锂 $\left(3860 \mathrm{mAh} \cdot \mathrm{g}^{-1}\right)$ 匹配, 实现更高的能量 密度 $1,23,28-34$ 。目前已研发出多种在室温下具有高 离子导率 (大于 $10^{-3} \mathrm{~S} \cdot \mathrm{cm}^{-1}$ ) 的无机固态电解质材 料 ${ }^{35-39}$ 。目前极具前景的体系为硫化物类固态电解 质和氧化物类固态电解质。氧化物类固态电解质 空气稳定性高, 但硬度较大, 界面接触差, 通过简 单冷压后界面电阻较大 ${ }^{21,40-44}$ 。硫化物类固态电解
质硬度低, 界面接触好, 室温下离子导率可高达 $10^{-2} \mathrm{~S} \cdot \mathrm{cm}^{-1}$, 冷压后界面电阻低 ${ }^{28,45-50}$, 与以单质 硫为代表的高比能正极匹配性好, 可进一步构筑 全固态电池 ${ }^{51}$ 。

在小型模具电池中, 使用硫化物固态电解质的 固态电池已取得了与液态电池相媲美的性能 $45,52,53$ 。 然而, 面向实用体系的软包电池研究尚欠缺。固态 软包电池与固态模具电池的主要区别在于, (1)软 包电池的测试压力一般在 $\mathrm{kPa}$ 级或无压力下进 行, 较低压力下固固接触差; 而模具电池的测试压 力可达到 $\mathrm{MPa}$ 级, 降低了固固接触问题对界面离 子传输的影响。(2)软包电池横截面面积大, 一般 为9-100 $\mathrm{cm}^{2}$, 对界面稳定性、装配操作要求高; 而模具电池的面积较小, 一般为 $0.5-1.2 \mathrm{~cm}^{2}$ 。因此 相比模具电池, 在软包电池中有限的固固接触导 致的过高局部电流问题被放大, 使得固态软包电 池难以正常工作, 往往导致器件迅速失效。在负极 侧, 金属锂与无机固态电解质的界面反应复杂, 例 如金属锂与硫化物电解质发生界面化学/电化学反 应 $^{54-57}$, 生成一层离子导率低的针化层, 形成介稳 界面 ${ }^{58-60}$, 循环过程中有限的固固接触进一步恶 
化。此外, 由于粉末固态电解质层本身机械强度较 差, 孔隙率较大, 进一步加压虽然能改善锂负极与 固态电解质的接触, 但是也增加电解质层破裂的 风险。金属锂在高压下易蠕变, 穿过空隙或裂缝与 正极接触, 导致电池短路 ${ }^{61}$ 。因此, 在实用软包体 系中优化金属锂负极与固态电解质界面是实现高 安全、高比能固态电池的重要前提。

本文通过局部高盐电解液润湿金属锂负极与 固态电解质界面, 增加锂负极与硫化物固态电解 质界面的离子输运通路, 实现界面锂离子的快速 输运。

\section{2 实验部分}

\section{1 实验材料}

实验用到的试剂详见表1。

\section{2 软包电池的组装}

正极混料: 将LTO, $\mathrm{Li}_{7} \mathrm{P}_{3} \mathrm{~S}_{11}$ (LPS), 碳纳米管 (CNT)粉末按照 $1: 2: 1$ 的质量比加入到球磨罐中, 然后加入粘结剂丁腈橡胶(NBR) (4\%, 质量分数 $(w)$ 和分散溶剂二溴甲烷进行球磨。采用的球磨条 件为转速 $360 \mathrm{r} \cdot \mathrm{min}^{-1}$ 、球磨 $8 \mathrm{~h}$, 以此得到混合均匀 的正极浆料。将正极浆料刮涂于铝䇴上, 烘干, 得 到复合正极。刮涂流程在氩气手套箱中操作。复合 硫正极的制备过程同上, 在球磨混料前先在 $155^{\circ} \mathrm{C}$ 的热熔装置中将硫粉包覆在碳管上。

电解质压片: LPS固态电解质粉末与丁腈橡胶 按质量比 9:1加入到球磨罐中, 加入二溴甲烷, 360 $\mathrm{r} \cdot \mathrm{min}^{-1}$ 的转速, 球磨 $8 \mathrm{~h}$, 得到均匀分散的LPS浆料。 取浆料于 $33 \mathrm{~mm} \times 33 \mathrm{~mm}$ 的不锈钢模具中, 干燥, $300 \mathrm{MPa}$ 加压, 得到电解质片。上述流程均在氩气 手套箱中操作。

电池组装: 在 $33 \mathrm{~mm} \times 33 \mathrm{~mm}$ 的不锈钢模具 中放入压好的电解质片, 裁剪 $30 \mathrm{~mm} \times 30 \mathrm{~mm}$ 的正 极片置于电解质片上, 活性物质 $\mathrm{LTO}$ 与 $\mathrm{S}$ 的负载分
别为 1.3 与 $1.2 \mathrm{mg} \mathrm{cm}^{-2}, 300 \mathrm{MPa}$ 加压。将 $3.5 \mathrm{mmol}$ LiTFSI加入到 $1 \mathrm{~mL}$ HFE/DME (体积比 $1:$ ) 溶液 中, 振荡溶解, 得到局部高盐液态电解质。滴加 25 $\mu \mathrm{L}$ HFE-DME LiTFSI高盐电解质润湿 $30 \mathrm{~mm} \times 30$ $\mathrm{mm}$ 金属锂表面, 再将润湿的锂负极面贴于固态电 解质片上, 引出极耳, 铝塑膜封装, 完成固态软包 电池组装。上述流程均在干室中操作。

\section{3 电化学测试}

电池的充放电、循环稳定性、倍率等测试均使 用蓝电测试系统进行测试, $\mathrm{Li} \mid \mathrm{LTO}$ 与 $\mathrm{Li} \mid \mathrm{S}$ 固态软包 电池测试截止电压分别为1.4-2.4 V与 1.4-2.8 V。 阻抗测试使用Solartron 1470E电化学工作, 测试频 率 $0.1 \mathrm{~Hz}-1 \mathrm{MHz}$ 。

\section{3 结果与讨论}

在传统固态软包电池中, 锂负极与SSE有限的 固固接触导致锂负极/SSE界面离子输运能力低 下, 以致其在低倍率下也难以实现有效的充放电 循环。通过局部高盐界面润湿能够有效填补负极/ SSE界面的固固空隙, 同时大量的互联通离子输运 通道促进锂离子均匀沉积, 可以获得稳定循环的 固态软包电池(图1)。值得注意的是, 有机电解液 的引入增加了新的界面。在无界面润湿固态电池 中, 脱嵌时锂离子先通过金属锂与固态电解质之 间的钝化层, 再由固态电解质传导到正极。电解液 润湿锂负极之后, 电解液与金属锂快速反应形成 固液界面膜 $(\mathrm{SEI})$, 同时与固态电解质反应形成固 液界面钝化层(SLEI) ${ }^{15}$, 锂离子先通过金属锂与液 态电解质之间的SEI层, 进入到固态电解质与锂负 极之间的少量液态电解液中, 并形成溶剂化层, 穿 过液态电解液与固态电解质之间的SLEI, 脱溶剂 化, 再通过固态电解质传导到正极。通常, 锂离子 在界面的传输需要克服的能垒最大, 是离子传导 的决速步骤 62 。锂离子界面传输的阻抗可通过阻抗

表1 实验中主要材料与试剂表

Table 1 Main chemical reagent

\begin{tabular}{lll}
\hline \multicolumn{1}{c}{ Reagent } & \multicolumn{1}{c}{ Parameters } & Company \\
\hline $\mathrm{Li}_{4} \mathrm{TI}_{5} \mathrm{O}_{12}$ & Size: $50-300 \mathrm{~nm}$ & Aladdin \\
$\mathrm{Li}_{7} \mathrm{P}_{3} \mathrm{~S}_{11}$ & Size: $1-5 \mu \mathrm{m}$, Conductivity: $0.64 \mathrm{mS} \cdot \mathrm{cm}^{-1}$ & HF-Kejing \\
$\mathrm{HFE}$ & $99.9 \%$ & DoDoChem \\
$\mathrm{DME}$ & $99.9 \%$ & DoDoChem \\
LiTFSI & $99.9 \%$ & DoDoChem \\
Dibromomethane & $99.9 \%$ & Aladdin \\
$\mathrm{NBR}$ & Molecular weight: $200000-300000$ & Aladdin \\
$\mathrm{S}$ & Particle size $<50 \mu \mathrm{m}$ & Jiangsu Cnano Technology Co., Ltd \\
Li metal & Thickness: $100 \mu \mathrm{m}$ & China Energy Lithium Co., Ltd. Aladdin \\
CNT & Specific area $200-500 \mathrm{~m}^{2} \cdot \mathrm{g}^{-1}$ & \\
\hline
\end{tabular}




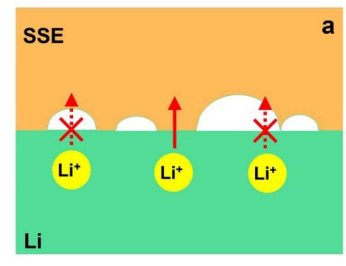

SSE: solid electrolyte

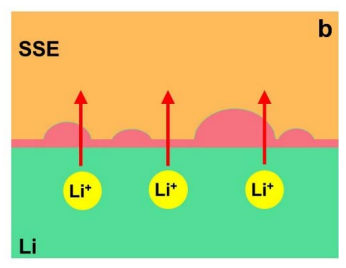

$\bigcirc$ Void
Wetting layer
图 1 金属锂负极与固态电解质界面锂离子输运的示意图

Fig. 1 Schematic of lithium ion transportation at the interfaces between lithium metal anode and solid electrolyte.

(a) Without and (b) with liquid phase therapy.

测试获得。

为研究界面润湿对离子传输的影响, 组装了 金属锂固态软包电池, 并对软包电池的截面及润 湿前后软包电池的阻抗图谱进行了分析。如图2a 所示, 固态电解质片在微观下不平整, 经真空封装 后的固态电解质与金属锂界面容易形成空隙, 造 成局部电流过高。阻抗图谱由高频的半圆和低频 的直线组成。半圆部分为锂离子转移电阻, 表征界 面传输阻力, 包括锂离子在电解质与负极界面, 液 态电解液与固态电解质界面, 电解质与正极界面,
以及正极内部颗粒间界面等。通过等效电路拟合, 可得电池中界面传输电阻。无界面润湿的 Li| LTO 固态软包电池的阻抗达到 $4366 \Omega \cdot \mathrm{cm}^{-2}$ (图2b), 而 施加3 $\mathrm{MPa}$ 压力后, 电池的界面阻抗迅速降低到 $340 \Omega \cdot \mathrm{cm}^{-2}$, 加压能够显著提升界面固固接触(图 2c)。但同时也增加了电解质片碎裂的风险。高盐 润湿负极/SSE界面后的 Li $\mid \mathrm{LTO}$ 固态电池的界面电 阻降低到64 $\Omega \cdot \mathrm{cm}^{-2}$ (图2d)。对比无界面润湿的固 态软包电池, $3 \mu \mathrm{L} \mathrm{cm}^{-2}$ 的HFE-DME LiTFSI局部高 盐润湿极大改善了锂负极与固态电解质的界面接 触, 甚至优于高压下的固固接触。这是因为局部高 盐具有流动性, 能有效填充电极与电解质片的空 隙。由此可见, 软包电池在无压力测试条件下, 锂 负极/SSE界面有限的固固接触是限制锂离子传输 的主要障碍, 高盐界面润湿增加了电极与电解质 的接触, 显著降低锂负极/SSE界面传输离子阻力。

为进一步验证负极界面润湿对界面离子输运 能力的提升, 组装了 $\mathrm{Li} \mid \mathrm{LTO}$ 固态软包电池, 对比润 湿前后电池的性能。如图 $3 \mathrm{a}$, 在 $25^{\circ} \mathrm{C}$ 下, 电池在 $0.1 C$ 循环, 比容量为 $107 \mathrm{mAh} \cdot \mathrm{g}^{-1}$, 循环 10 圈与 20 圈后，容量保持率分别为 $99 \%$ 与 $92 \%$ 。值得关注的 是, 润湿后的 $\mathrm{Li} \mid \mathrm{LTO}$ 固态软包电池还能实现高倍
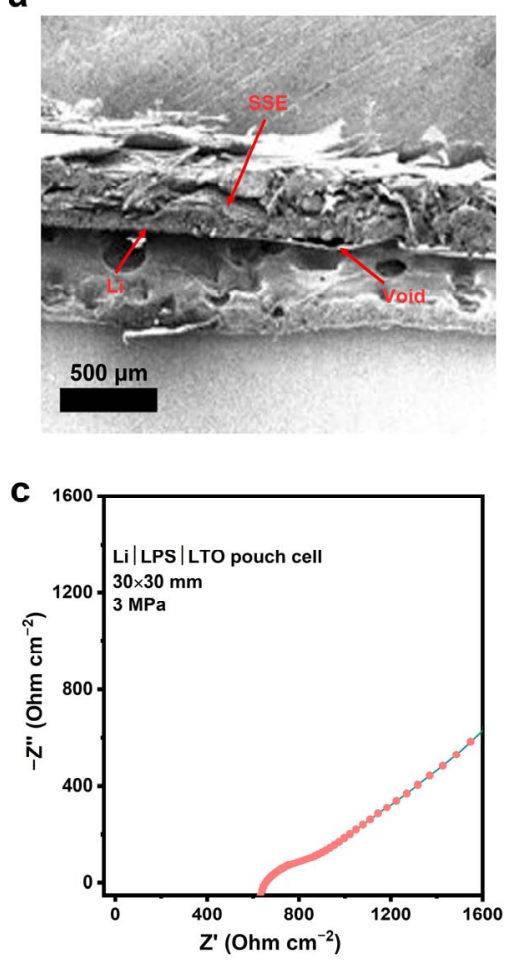
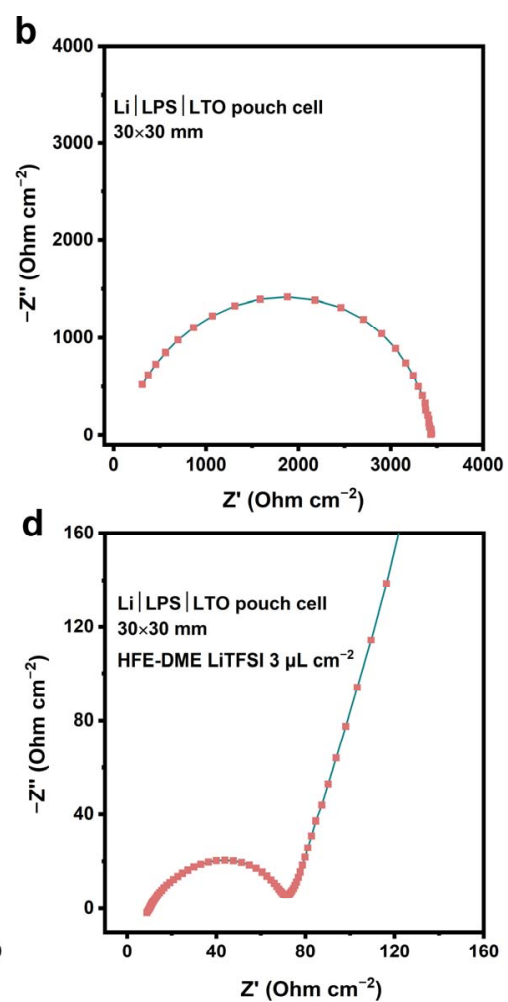

图 2 (a) Li|LTO 固态软包电池的截面 SEM 图; 固态软包电池的阻抗图谱: (b)无界面润湿, 无压力,

(c) $3 \mathrm{MPa}$ 压力, (d) HFE-DME LiTFSI 润湿金属锂负极/固态电解质界面

Fig. 2 (a) SEM cross-section of Li|LTO solid-state pouch cell; impedance spectrum of pouch cells: (b) without liquid phase therapy and pressure, (c) 3 MPa pressure, (d) wetting with HFE-DME LiTFSI liquid electrolyte. 

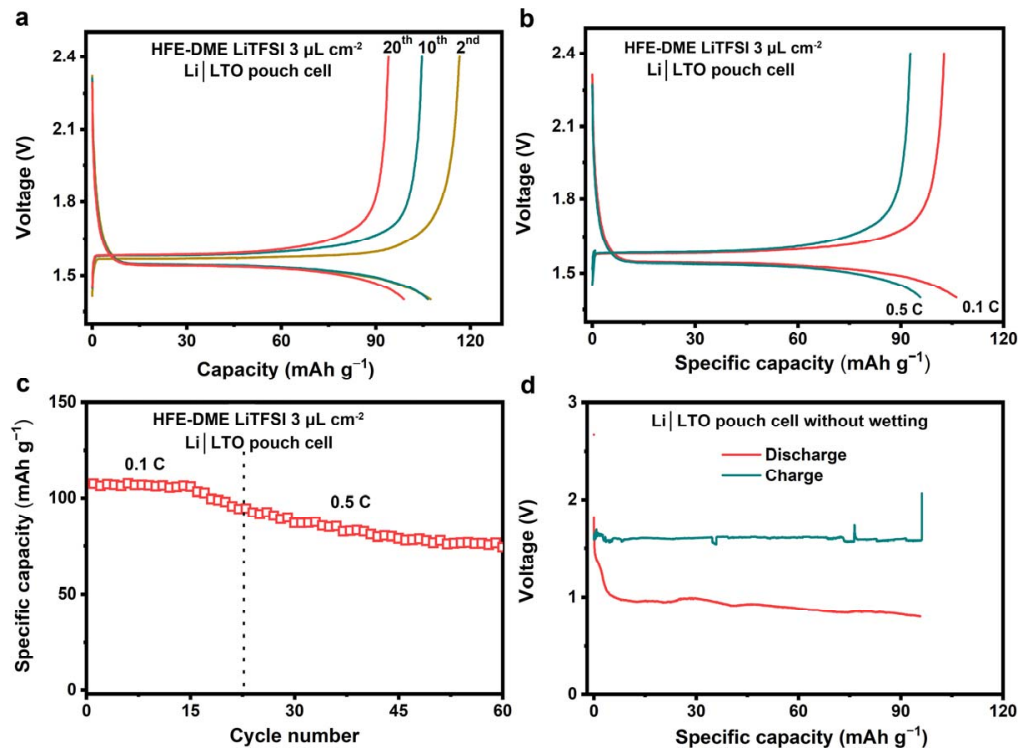

图 $3 \mathrm{Li} \mid$ LTO 固态软包电池的性能图

Fig. 3 The cycling performances of Li|LTO solid pouch cells.

(a) Charge-discharge profiles, (b) rate performance, and (c) cycle stability of Li|LTO solid pouch cell with liquid phase therapy.

(d) charge-discharge profiles of Li|LTO solid pouch cell without liquid phase therapy. The batteries are operated under room temperature $\left(25^{\circ} \mathrm{C}\right)$.

率下的循环, $0.5 C$ 循环比容量为 $96 \mathrm{mAh} \cdot \mathrm{g}^{-1}, 20$ 圈 后容量保持率 $89 \%$ 。此外, 固态软包电池在 $0.5 C$ 下 稳定循环 60 圈后, 容量仍可达到 $74 \mathrm{mAh} \cdot \mathrm{g}^{-1}$ 。相比 之下, 未润湿的 $\mathrm{Li} \mid \mathrm{LTO}$ 固态软包电池首圈 $0.1 C$ 放 电后, 不能充回截止电压, 极化显著增加, 出现微 短路。这是由于锂负极与SSE有限的固固接触导致 的局部电流过大所致。

界面润湿策略还可应用于实用化全电池体 系。如图4所示, $\mathrm{Li} \mid \mathrm{S}$ 软包全电池在 $0.01 C$ 及 $0.02 C$ 的 倍率下的电池比容量分别达到 1100 与 $932 \mathrm{mAh} \cdot \mathrm{g}^{-1}$ 。

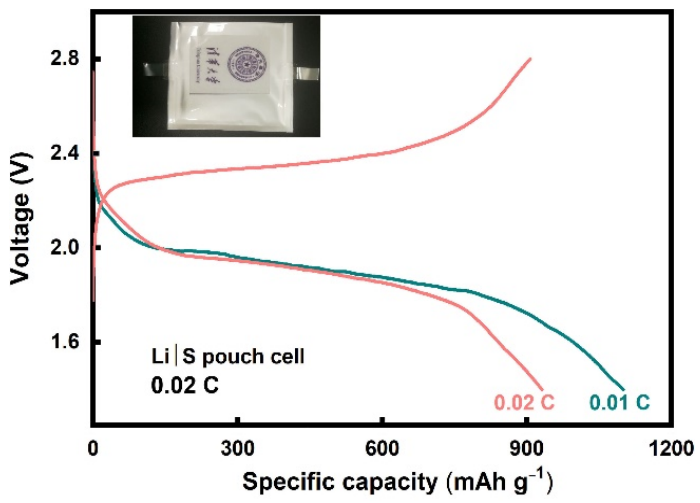

图 $4 \mathrm{Li} \mid \mathrm{S}$ 固态软包电池的充放电曲线

Fig. 4 The charge-discharge profiles of $\mathrm{Li} \mid \mathrm{S}$ solid pouch cell with a liquid phase therapy.

Inset is the digital photograph of a $\mathrm{Li} \mid \mathrm{S}$ pouch cell, where the $\mathrm{Li}$ anode/solid electrolytes interface is wetted with HFE-DME LiTFSI liquid electrolyte. The pouch cell size is $30 \mathrm{~mm} \times 30 \mathrm{~mm}$. The battery is tested under $25^{\circ} \mathrm{C}$.
相对于Li|LTO固态软包电池, 在相近活性负载下, 锂硫电池体系中硫正极的容量更高。本文中, 锂硫 体系中金属锂循环容量是LTO软包电池的9.5倍。 放电时, 金属锂负极的锂离子脱嵌会造成部分金 属锂与固态电解质脱离接触, 离子输运通路减少; 沉积过程中, 大片电池的不均匀性易导致局部电 流增加, 更容易形成锂枝晶, 形成死锂甚至导致电 池失效。因此单位面积内锂离子脱出嵌入的容量 越大, 对界面的要求越高。此外, 不同于液态锂硫 电池在 $2.0 \mathrm{~V}$ (固相多硫化物)与 $2.3 \mathrm{~V}$ (液相多硫化 物) 附近出现两个放电平台, $\mathrm{Li} \mid \mathrm{S}$ 固态电池在放电 过程中仅在 $2.0 \mathrm{~V}$ 附近出现斜坡, 表现出固态电池 的充放电行为。这说明加入少量的液态电解液主 要在锂负极/SSE界面起润湿作用。

由此可见, 金属锂与固态电解质层有限的点 点接触 $45,53,63$ 严重限制了固态软包电池 Li/SSE界面 锂离子的传输, 相对于模具电池 ${ }^{62}$, 高能量密度的 固态软包电池对 Li/SSE界面也提出了更高的要 求, 局部高盐的界面润湿体系能与金属锂和硫化 物固态电解质同时形成稳定的界面, 增加了界面 接触, 降低了界面离子传输阻力。

\section{4 结论}

本文通过HFE-DME LiTFSI局部高盐液态电 解液润湿锂负极/硫化物电解质界面, 极大的改善 了界面的离子传输能力, 将Li|LTO固态软包电池 的界面电阻从4366降低到 $64 \Omega \cdot \mathrm{cm}^{-2}$, 从而实现了 
$30 \mathrm{~mm} \times 30 \mathrm{~mm} \mathrm{Li} \mid \mathrm{LTO}$ 固态软包电池的稳定循环。 在 $0.1 C$ 下比容量为 $107 \mathrm{mAh} \cdot \mathrm{g}^{-1}$, 循环 10 圈与 20 圈 后, 容量保持率分别为 $99 \%$ 与 $92 \%$ 。 $0.5 C$ 下比容量 为 $96 \mathrm{mAh} \cdot \mathrm{g}^{-1}$, 循环 60 圈后, 比容量仍可达到 74 $\mathrm{mAh} \cdot \mathrm{g}^{-1}$ 。进一步, 在更加苛刻的 $30 \mathrm{~mm} \times 30 \mathrm{~mm} \mathrm{Li} \mid \mathrm{S}$ 固态软包电池体系下实现可逆充放电循环。 $0.01 C$ 及 $0.02 C$ 的放电容量分别达到 1100 与 $932 \mathrm{mAh} \cdot \mathrm{g}^{-1}$ 。 同时, 界面润湿策略也有望推广至其它固态电解 质体系, 如以氧化物固态电解质为基础的固态电 池, 为固态软包电池走向实用化提供了有效的策 略。

\section{References}

(1) Cheng, X. B.; Zhao, C. Z.; Yao, Y. X.; Liu, H.; Zhang, Q. Chem 2019, 5, 74. doi: 10.1016/j.chempr.2018.12.002

(2) Peng, H. J.; Huang, J. Q.; Cheng, X. B.; Zhang, Q. Adv. Energy Mater. 2017, 7, 1700260. doi: 10.1002/aenm.201700260

(3) Li, B. Q.; Kong, L.; Zhao, C. X.; Jin, Q.; Chen, X.; Peng, H. J.; Qin, J. L.; Chen, J. X.; Yuan, H.; Zhang, Q.; Huang, J. Q. InfoMat 2019, 1, 533. doi: 10.1002/inf2.12056

(4) Shen, X.; Cheng, X.; Shi, P.; Huang, J.; Zhang, X.; Yan, C.; Li, T.; Zhang, Q. J. Energy Chem. 2019, 37, 29. doi: 10.1016/j.jechem.2018.11.016

(5) Chen, J. X.; Zhang, X. Q.; Li, B. Q.; Wang, X. M.; Shi, P.; Zhu, W.; Chen, A.; Jin, Z.; Xiang, R.; Huang, J. Q. J. Energy Chem. 2020, 47, 128. doi: 10.1016/j.jechem.2019.11.024

(6) Jiang, J. H.; Wang, A. B.; Wang, W. K.; Jin, Z. Q.; Fan, L. Z. J. Energy Chem. 2020, 46, 114. doi: 10.1016/j.jechem.2019.10.009

(7) Yan, C.; Yuan, H.; Park, H. S. Huang, J. Q. J. Energy Chem. 2020, 47, 217. doi: 10.1016/j.jechem.2019.09.034

(8) Guo, F.; Chen, P.; Kang, T.; Wang, Y. L.; Liu, C. H.; Shen, Y. B.; Lu, W.; Chen, L. W. Acta Phys. -Chim. Sin. 2019, 35, 1365. [郭峰, 陈鹏, 康拓, 王亚龙, 刘承浩, 沈炎宾, 卢威, 陈立桅. 物理化学学报, 2019, 35, 1365.] doi: 10.3866/PKU.WHXB201903008

(9) Chen, K.; Sun, Z. H.; Fang, R. P.; Li, F.; Cheng, H. M. Acta Phys. -Chim. Sin. 2018, 34, 377. [陈克, 孙振华, 方若翩, 李峰, 成 会明. 物理化学学报, 2018, 34, 377.] doi: 10.3866/ PKU.WHXB201709001

(10) Oh, P.; Lee, H.; Park, S.; Cha, H.; Kim, J.; Cho, J. Adv. Energy Matter. 2020, 2000904. doi: 10.1002/aenm.202000904

(11) Cao, D.; Sun, X.; Li, Q.; Natan, A.; Xiang, P.; Zhu, H. Matter 2020, 2, 1. doi: 10.1016/j.matt.2020.03.015

(12) Zhang, X. Q.; Zhao, C. Z.; Huang, J. Q. Zhang, Q. Engineering 2018, 4, 831. doi: 10.1016/j.eng.2018.10.008

(13) Zhao, C. Z.; Duan, H.; Huang, J. Q.; Zhang, J.; Zhang, Q.; Guo, Y. G.; Wan, L. J. Sci. China Chem. 2019, 62, 1286. doi: 10.1007/s11426-019-9519-9

(14) Ates, T.; Keller, M.; Kulisch, J.; Adermann, T. Passerini, S. Energy Storage Mater. 2019, 17, 204. doi: 10.1016/j.ensm.2018.11.011

(15) Busche, M. R.; Drossel, T.; Leichtweiss, T.; Weber, D. A.; Falk, M.; Schneider, M.; Reich, M. L.; Sommer, H.; Adelhelm, P.; Janek, J. Nat. Chem. 2016, 8, 426. doi: 10.1038/nchem.2470

(16) Sakuda, A.; Sato, Y.; Hayashi, A.; Tatsumisago, M. Energy Technol. 2019, 7, 1900077. doi: 10.1002/ente.201900077

(17) Shen, Y. Q.; Zeng, F. L.; Zhou, X. Y.; Wang, A. B.; Wang, W. K.; Yuan, N. Y.; Ding, J. N. J. Energy Chem. 2020, 48, 267. doi: 10.1016/j.jechem.2020.01.016

(18) Wu, J. Y.; Ling, S. G.; Yang, Q.; Li, H.; Xu, X. X.; Chen, L. Q. Chin Phys. B 2016, 25, 078204. doi: 10.1088/1674-1056/25/7/078204

(19) Yao, X. Y.; Huang, N.; Han, F. D.; Zhang, Q.; Wan, H. L.; Mwizerwa, J. P.; Wang, C. S.; Xu, X. X. Adv. Energy Mater. 2017, 7, 1602923. doi: 10.1002/aenm.201602923

(20) Zhang, H.; Judez, X.; Santiago, A.; Martinez-Ibanez, M.; MunozMarquez, M. A.; Carrasco, J.; Li, C. M.; Eshetu, G. G.; Armand, M. Adv. Energy Mater. 2019, 9, 1900763. doi: 10.1002/aenm.201900763

(21) Xu, R.; Zhang, S.; Wang, X.; Xia, Y.; Xia, X.; Wu, J.; Gu, C.; Tu, J. Chem. -A Eur. J. 2018, 24, 6007. doi: 10.1002/chem.201704568

(22) Zhao, C. Z.; Zhang, X. Q.; Cheng, X. B.; Zhang, R.; Xu, R.; Chen, P. Y.; Peng, H. J.; Huang, J. Q. Zhang, Q. Proc. Natl. Acad. Sci. 2017, 114, 11069. doi: 10.1073/pnas.1708489114

(23) Hou, L. P.; Yuan, H.; Zhao, C. Z.; Xu, L.; Zhu, G. L.; Nan, H. X.; Cheng, X. B.; Liu, Q. B.; He, C. X.; Huang, J. Q.; Zhang, Q. Energy Storage Mater. 2019, 25, 436. doi: 10.1016/j.ensm.2019.09.037

(24) Zhang, Q.; Cao, D. X.; Ma, Y.; Natan, A.; Aurora, P. Zhu, H. L. Adv. Mater. 2019, 31, 1901131. doi: 10.1002/adma.201901131

(25) Zhang, Y. B.; Chen, R. J.; Wang, S.; Liu, T.; Xu, B. Q.; Zhang, X.; Wang, X. Z.; Shen, Y.; Lin, Y. H.; Li, M.; et al. Energy Storage Mater. 2020, 25, 145. doi: 10.1016/j.ensm.2019.10.020

(26) Zhang, Y. B.; Liu, T.; Zhang, Q. H.; Zhang, X.; Wang, S.; Wang, X. Z.; Li, L. L.; Fan, L. Z.; Nan, C. W.; Shen, Y. J. Mater. Chem. A 2018, 6, 23345. doi: $10.1039 / \mathrm{c} 8 \mathrm{ta} 08420 \mathrm{c}$

(27) Jin, C. Q.; Xie, K.; Hong, X. B. Acta Chim. Sin. 2014, 72, 11. doi: 10.6023/A13101097

(28) Cheng, X. B.; Zhang, R.; Zhao, C. Z.; Zhang, Q. Chem. Rev. 2017, 117, 10403. doi: 10.1021/acs.chemrev.7b00115

(29) Yan, M.; Liang, J. Y.; Zuo, T. T.; Yin, Y. X.; Xin, S.; Tan, S. J.; Guo, Y. G.; Wan, L. J. Adv. Funct. Mater. 2020, 30, 1908047. doi: 10.1002/adfm.201908047

(30) Oh, D. Y.; Kim, D. H.; Jung, S. H.; Han, J. G.; Choi, N. S.; Jung, Y. S. J. Mater. Chem. A 2017, 5, 20771. doi: 10.1039/c7ta06873e

(31) Chen, L.; Fan, L. Z. Energy Storage Mater. 2018, 15, 37. doi: 10.1016/j.ensm.2018.03.015 
(32) Fan, Z.; Ding, B.; Zhang, T.; Lin, Q.; Malgras, V.; Wang, J.; Dou, H.; Zhang, X.; Yamauchi, Y. Small 2019, 15, 1903952.

doi: $10.1002 / \mathrm{smll} .201903952$

(33) Gao, Z.; Zhang, S.; Huang, Z.; Lu, Y.; Wang, W.; Wang, K.; Li, J.; Zhou, Y.; Huang, L.; Sun, S. Chin. Chem. Lett. 2019, $30,525$. doi: 10.1016/j.cclet.2018.05.016

(34) Jiang, J. H.; Wang, A. B.; Wang, W. K.; Jin, Z. Q.; Fan, L. Z. J. Energy Chem. 2020, 46, 114. doi: 10.1016/j.jechem.2019.10.009

(35) Kato, Y.; Hori, S.; Saito, T.; Suzuki, K.; Hirayama, M.; Mitsui, A.; Yonemura, M.; Iba, H.; Kanno, R. Nat. Energy 2016, 1, 16030. doi: 10.1038/nenergy.2016.30

(36) Deiseroth, H. J.; Kong, S. T.; Eckert, H.; Vannahme, J.; Reiner, C.; Zaiß, T.; Schlosser, M. Angew. Chem. Int. Ed. 2008, 47, 755. doi: 10.1002/anie. 200703900

(37) Kamaya, N.; Homma, K.; Yamakawa, Y.; Hirayama, M.; Kanno, R.; Yonemura, M.; Kamiyama, T.; Kato, Y.; Hama, S.; Kawamoto, K.; Mitsui, A. Nat. Mater. 2011, 10, 682. doi: 10.1038/nmat3066

(38) Manalastas, W.; Rikarte, J.; Chater, R. J.; Brugge, R.; Aguadero, A.; Buannic, L.; Llordés, A.; Aguesse, F.; Kilner, J. J. Power Sources 2019, 412, 287. doi: 10.1016/j.jpowsour.2018.11.041

(39) Xu, X. X.; Qiu, Z. J.; Guan, Y. B.; Huang, Z.; Jin, Y. Energy Storage Sci. Technology 2013, 2, 332. [许晓雄, 邱志军, 官亦标, 黄祯, 金翼. 储能科学与技术, 2013, 2, 332 . doi: 10.3969/j.issn.2095-4239.2013.04.001

(40) He, M.; Cui, Z.; Han, F.; Guo, X. J. Alloy. Compd. 2018, 762, 157. doi: 10.1016/j.jallcom.2018.05.255

(41) Chen, W.; Lei, T.; Wu, C.; Deng, M.; Gong, C.; Hu, K.; Ma, Y.; Dai, L.; Lv, W.; He, W.; et al. Adv. Energy Mater. 2018, 8, 1702348. doi: 10.1002/aenm.201702348

(42) Miura, A.; Rosero-Navarro, N. C.; Sakuda, A.; Tadanaga, K.; Phuc, N. H. H.; Matsuda, A.; Machida, N.; Hayashi, A. Tatsumisago, M. Nat. Rev. Chem. 2019, 3, 189. doi: 10.1038/s41570-019-0078-2

(43) Liang, Y.; Zhang, W.; Wu, D.; Ni, Q. Q.; Zhang, M. Q. Adv. Mater. Interfaces 2018, 5, 1800430. doi: 10.1002/admi.201800430

(44) Zhang, Q.; Ding, Z.; Liu, G.; Wan, H.; Mwizerwa, J. P.; Wu, J.; Yao, X. Energy Storage Mater. 2019, 23, 168. doi: 10.1016/j.ensm.2019.05.015

(45) Chen, R.; Li, Q.; Yu, X.; Chen, L.; Li, H. Chem. Rev. 2019, doi: 10.1021/acs.chemrev.9b00268

(46) Teragawa, S.; Aso, K.; Tadanaga, K.; Hayashi, A.; Tatsumisago, M. J. Power Sources 2014, 248, 939. doi: 10.1016/j.jpowsour.2013.09.117

(47) Tsukasaki, H.; Mori, Y.; Otoyama, M.; Yubuchi, S.; Asano, T.; Tanaka, Y.; Ohno, T.; Mori, S.; Hayashi, A.; Tatsumisago, M. Sci. Rep. 2018, 8, 6214. doi: 10.1038/s41598-018-24524-7
(48) Hayashi, A.; Noi, K.; Sakuda, A.; Tatsumisago, M. Nat. Commun. 2012, 3, 856. doi: 10.1038/ncomms 1843

(49) Jin, F., Li. J.; Hu, C. J.; Dong, H. C.; Chen, P.; Shen, Y. B.; Chen, L. W. Acta Phys. -Chim. Sin. 2019, 35, 1399. [金锋, 李静, 胡晨吉, 董厚才, 陈鹏, 沈炎宾, 陈立桅. 物理化学学报, 2019, 35, 1399.] doi: 10.3866/PKU.WHXB201904085

(50) Fei, H. F.; Liu, Y. P.; Wei, C. L.; Zhang, Y. C.; Feng, J. K.; Chen, C. Z.; Yu, H. J. Acta Phys. -Chim. Sin. 2020, 36, 1905015. [费慧芳, 刘 永鹏, 魏传亮, 张显婵, 冯金奎, 陈传忠, 于慧君. 物理化学学报, 2020, 36, 1905015.] doi: 10.3866/PKU.WHXB201905015

(51) Yuan, H.; Nan, H. X.; Zhao, C. Z.; Zhu, G. L.; Lu, Y.; Cheng, X. B.; Liu, Q. B.; He, C. X.; Huang, J. Q.; Zhang, Q. Batteries \& Supercaps 2020. doi: 10.1002/batt.202000051

(52) Zhu, G. L.; Zhao, C. Z.; Huang, J. Q.; He, C.; Zhang, J.; Chen, S.; Xu, L.; Yuan, H.; Zhang, Q. Small 2019, 15, 1805389. doi: $10.1002 /$ smll.201805389

(53) Xu, L.; Tang, S.; Cheng, Y.; Wang, K.; Liang, J.; Liu, C.; Cao, Y. C.; Wei, F.; Mai, L. Joule 2018, 2, 1991. doi: 10.1016/j.joule.2018.07.009

(54) Wenzel, S.; Weber, D. A.; Leichtweiss, T.; Busche, M. R.; Sann, J.; Janek, J. Solid State Ionics 2016, 286, 24. doi: 10.1016/j.ssi.2015.11.034

(55) Wenzel, S.; Leichtweiss, T.; Krüger, D.; Sann, J.; Janek, J. Solid State Ionics 2015, 278, 98. doi: 10.1016/j.ssi.2015.06.001

(56) Swamy, T.; Chen, X.; Chiang, Y. M. Chem. Mater. 2019, 31, 707. doi: 10.1021/acs.chemmater.8b03420

(57) Zhang, Q.; Huang, N.; Huang, Z.; Cai, L.; Wu, J.; Yao, X. J. Energy Chem. 2020, 40, 151. doi: 10.1016/j.jechem.2019.03.006

(58) Tan, D. H. S.; Wu, E. A.; Nguyen, H.; Chen, Z.; Marple, M. A. T.; Doux, J. M.; Wang, X.; Yang, H.; Banerjee, A. Meng, Y. S. ACS Energy Lett. 2019, 4, 2418. doi: 10.1021/acsenergylett.9b01693

(59) Sang, L.; Haasch, R. T.; Gewirth, A. A.; Nuzzo, R. G. Chem. Mater. 2017, 29, 3029. doi: 10.1021/acs.chemmater.7b00034

(60) Zhang, W.; Leichtweiß, T.; Culver, S. P.; Koerver, R.; Das, D.; Weber, D. A.; Zeier, W. G.; Janek, J. ACS Appl. Mater. Interfaces 2017, 9 , 35888. doi: 10.1021/acsami.7b11530

(61) Doux, J. M.; Nguyen, H.; Tan, D. H. S.; Banerjee, A.; Wang, X.; Wu, E. A.; Jo, C.; Yang, H.; Meng, Y. S. Adv. Energy Mater. 2019, 10, 1903253. doi: 10.1002/aenm.201903253

(62) Zhao, C. Z.; Zhao, B. C.; Yan, C.; Zhang, X .Q.; Huang, J. Q.; Mo, Y.; Xu, X.; Li, H.; Zhang, Q. Energy Storage Mater. 2019, 24, 75. doi: 10.1016/j.ensm.2019.07.026

(63) Liu, H.; Cheng, X. B.; Huang, J. Q.; Yuan, H.; Lu, Y.; Yan, C.; Zhu, G. L.; Xu, R.; Zhao, C. Z.; Hou, L .P.; et al. ACS Energy Lett. 2020, 5, 833. doi: 10.1021/acsenergylett.9b02660 